\title{
PAPER
}

CrossMark $\leftarrow$ click for updates

Cite this: Phys. Chem. Chem. Phys., $2016,18,7300$

Received 23rd December 2015 Accepted 12th February 2016

DOI: $10.1039 / c 5$ cp07941a

www.rsc.org/pccp

\section{Halogen bonding. The role of the polarizability of the electron-pair donor}

\begin{abstract}
Dario J. R. Duarte, ${ }^{* a}$ Gladis L. Sosa, ${ }^{b}$ Nélida M. Peruchena ${ }^{a}$ and Ibon Alkortac
The nature of $\mathrm{F}-\mathrm{Br} \cdots \mathrm{X}-\mathrm{R}$ interactions (with $\mathrm{X}=\mathrm{F}, \mathrm{Cl}, \mathrm{Br}, \mathrm{I}$ and $\mathrm{R}=-\mathrm{H},-\mathrm{F}$ ) has been investigated through theoretical calculation of molecular potential electrostatic (MEP), molecular polarizability, atoms in molecules (AIM) analysis and energetic decomposition analysis (EDA). A detailed analysis of the MEPs reveals that considering only the static electrostatic interactions is not sufficient to explain the nature of these interactions. The molecular polarizabilities of $X-R$ molecules suggest that the deformation capacity of the electronic cloud of the lone pairs of the $X$ atom plays an important role in the stability of these complexes. The topological analysis of the $L(\mathbf{r})=-\frac{1}{4} \nabla^{2} \rho(\mathbf{r})$ function and the detailed analysis of the atomic quadrupole moments reveal that the $\mathrm{Br}$...X interactions are electrostatic in nature. The electron acceptor $\mathrm{Br}$ atom causes a polarization of the electronic cloud (electronic induction) on the valence shell of the $X$ atom. Finally, the electrostatic forces and charge transfer play an important role not only in the stabilization of the complex, but also in the determination of the molecular geometry of equilibrium. The dispersive and polarization forces do not influence the equilibrium molecular geometry.
\end{abstract}

\section{Introduction}

Non-covalent interactions, such as halogen bonds (XBs), are involved in a vast number of phenomena related to the realm of molecular and macromolecular science. There are many $\mathrm{XB}$ studies that focus their attention on the $\sigma$-hole concept. ${ }^{1-7}$ This explains many features of these interactions. However, there are only a few papers that investigate the polarizability of the lone pairs of the Lewis bases forming a XB..$^{3,6,8}$

On the other hand, recently Qi et al. ${ }^{9}$ have studied theoretically the unusual stability of XBs that occur between the $\mathrm{B}_{3}$ aromatic ring in $(\mathrm{BNN})_{3}{ }^{+}$and dihalogenated molecules $\mathrm{X} 1-\mathrm{X} 2(\mathrm{X} 1, \mathrm{X} 2=\mathrm{F}, \mathrm{Cl}, \mathrm{Br})$, finding the following order of relative stabilities: F-F.. ${ }^{+}(\mathrm{BNN})_{3}<$ $\mathrm{F}-\mathrm{Cl}^{\delta+} \ldots{ }^{+}(\mathrm{BNN})_{3}<\mathrm{Cl}-\mathrm{Cl} \ldots{ }^{+}(\mathrm{BNN})_{3}<\mathrm{Cl}-\mathrm{Br}^{\delta+} \ldots{ }^{+}(\mathrm{BNN})_{3}<\mathrm{Br}-$ $\mathrm{Br} \cdot{ }^{+}(\mathrm{BNN})_{3}<\mathrm{F}-\mathrm{Br}^{\delta+} \ldots{ }^{+}(\mathrm{BNN})_{3}$, calculated at the MP2/aug-ccpVDZ level. The joint analysis of charge transfer, natural bond orbital (NBO), quantum theory of atoms in molecules (QTAIM), and changes in the electron density suggests that the three membered aromatic ring of $(\mathrm{BNN})_{3}{ }^{+}$can act as an electron donor to form a

\footnotetext{
${ }^{a}$ Laboratorio de Estructura Molecular y Propiedades, Área de Química Física, Departamento de Química, Facultad de Ciencias Exactas y Naturales y Agrimensura, Universidad Nacional del Nordeste, Avda. Libertad 5460, (3400) Corrientes, Argentina.E-mail:djr_duarte@hotmail.com

${ }^{b}$ Laboratorio de Química Teórica y Experimental, Departamento de Química. Facultad Regional Resistencia, Universidad Tecnológica Nacional, French 414, (3500) Resistencia, Chaco, Argentina

${ }^{c}$ Instituto de Química Médica, CSIC, Juan de la Cierva, 3, E-28006 Madrid, Spain $\dagger$ Electronic supplementary information (ESI) available. See DOI: 10.1039/ c5cp07941a
}

$\pi$-halogen bond. Wang et al. demonstrated in a theoretical study that the $\mathrm{FBr} \cdots \mathrm{BrF}$ and $\mathrm{FH} \cdot \mathrm{BrF}$ complexes are capable of existing in the gaseous phase, even when the interaction occurs between positively charged atoms $\left(\mathrm{Br}^{\delta+} \ldots{ }^{\delta+} \mathrm{Br}\right.$ and $\left.\mathrm{H}^{\delta+} \ldots{ }^{\delta+} \mathrm{Br}\right)$. These authors attribute the stability of these interactions to the great contribution of the dispersion energy which leads to the formation of instantaneous multipoles. ${ }^{10}$

Other examples of stabilizing interactions between positively charged atoms are in the work of Blanco et al., who have studied a series of complexes formed between carbon monoxide and hipohalogenated acids: $\mathrm{XOH} \cdots \mathrm{CO}, \mathrm{XOH} \cdots \mathrm{OC}, \mathrm{HOX} \cdots \mathrm{CO}$ and HOX . . OC (where X = F, Cl, Br, I). Notably, the strongest complexes in this series are the type $\left(\mathrm{A}-\mathrm{H}^{\delta+} \ldots{ }^{\delta+} \mathrm{CO}\right.$ and $\left.\mathrm{A}-\mathrm{I}^{\delta+} \ldots{ }^{\delta+} \mathrm{CO}\right)$, with interaction energies between 5 and $7 \mathrm{~kJ} \mathrm{~mol}^{-1}$ higher than type HOX...CO and HOX...OC in which the interacting atoms carry opposite charges. ${ }^{11}$ It is important to note that in carbon monoxide, the carbon atom is positively charged $(\approx+1.2 e) .{ }^{12,13}$

From an intuitive point of view, it seems unlikely that stabilizing interactions occur between positively charged atoms. However, it is known that when atoms are part of a molecule, their spherical electron cloud is deformed and they are able to polarize (i.e. form instantaneous and induced multipoles) in the presence of an external electric field. We consider that the study of such systems will allow us to understand the role of the polarizability of the electron-pair donor of the Lewis base in XBs. In this context the question arises: what are the electronic rearrangements experienced by the halogens in binding situations? And what are the physical principles that explain the unusual stability of interactions between positively 
charged halogen atoms? In order to address this issue, in this work the nature of $\mathrm{F}-\mathrm{Br} \cdots \mathrm{X}-\mathrm{R}$ interactions (with $\mathrm{X}=\mathrm{F}, \mathrm{Cl}, \mathrm{Br}$, $\mathrm{I}$ and $\mathrm{R}=-\mathrm{H},-\mathrm{F}$ ) has been investigated through theoretical calculations of molecular electrostatic potential (MEP), molecular polarizability, atoms in molecules (AIM) analysis and energetic decomposition analysis (EDA).

\section{Computational details}

All electronic structure calculations were performed with the Gaussian 03 program package. ${ }^{14}$ The geometries of monomers and complexes were optimized without any restriction using the second-order Møller Plesset perturbation theory (MP2) ${ }^{15}$ with the aug-cc-pVTZ basis set for $\mathrm{H}, \mathrm{F}$ and $\mathrm{Br}$ atoms and the def2-TZVPP basis set iodine atom. All stationary points were confirmed as minimum energy by the absence of imaginary frequencies.

The MP2/CBS (CBS = complete basis set) energies have been calculated by using the extrapolations scheme proposed by Helgaker et al. (eqn (1)-(5)). ${ }^{16,17}$ Here, $\alpha=1.54$ and $X$ is the cardinal number of the employed basis set: 3 for aug-cc-pVTZ (def2-TZVPP for iodine) and 4 for aug-cc-pVQZ (def2-QZVPP for iodine). Additionally, the contribution of the $\operatorname{CCSD}(\mathrm{T})$ energy calculated with the aug-cc-pVTZ basis set has been added to the MP2/CBS to obtain a $\operatorname{CCSD}(\mathrm{T})$ quality energy following the recommendations of Hobza et al. (eqn (6)). ${ }^{18}$

$$
\begin{gathered}
E_{\mathrm{X}}^{\mathrm{HF}}=E_{\mathrm{CBS}}^{\mathrm{HF}}+\mathrm{Be}^{-X \alpha} \\
E_{\mathrm{CBS}}^{\mathrm{HF}}=\frac{E_{4}^{\mathrm{HF}} \mathrm{e}^{4 \alpha}-E_{3}^{\mathrm{HF}} \mathrm{e}^{3 \alpha}}{\mathrm{e}^{4 \alpha}-\mathrm{e}^{3 \alpha}} \\
E_{\mathrm{coor}, \mathrm{X}}^{\mathrm{MP} 2}=E_{\mathrm{X}}^{\mathrm{MP} 2}-E_{\mathrm{X}}^{\mathrm{HF}} \\
E_{\mathrm{coor}, \lim }^{\mathrm{MP} 2}=\frac{4^{3} E_{\mathrm{coor}, 4}^{\mathrm{MP} 2}-3^{3} E_{\mathrm{coor}, 3}^{\mathrm{MP} 2}}{4^{3}-3^{3}} \\
E_{\mathrm{CBS}}^{\mathrm{MP} 2}=E_{\mathrm{CBS}}^{\mathrm{HF}}+E_{\mathrm{coor}, \mathrm{Mim}}^{\mathrm{MP} 2} \\
E_{\mathrm{CBS}}^{\mathrm{CCSD}(\mathrm{T})}=E_{\mathrm{CBS}}^{\mathrm{MP} 2}+\left(E_{3}^{\mathrm{CCSD}(\mathrm{T})}-E_{3}^{\mathrm{MP} 2}\right)
\end{gathered}
$$

The total binding energy ( $\left.E_{\text {Bind }}\right)$ of each complex was calculated by subtracting the CBS energies of the isolated compounds from the energy of the complex.

The energy decomposition analysis (RVS) partition method ${ }^{19}$ has been used to compute the interaction energy terms using (eqn (7)).

$$
E_{\mathrm{Int}}=E_{\mathrm{ES}}+E_{\mathrm{EX}}+E_{\mathrm{POL}}+E_{\mathrm{CT}}+E_{\mathrm{Disp}}
$$

The four terms $E_{\mathrm{ES}}, E_{\mathrm{EX}}, E_{\mathrm{POL}}$ and $E_{\mathrm{CT}}$ were calculated by RVS method $^{19}$ implemented in the GAMESS program ${ }^{20}$ at HF/augcc-pVTZ level. The $E_{\text {Disp }}$ component has been estimated as the difference between the total interaction energy at the MP2/augcc-pVTZ level and the total interaction energy at the HF/aug-ccpVTZ level. The topological analysis of electron charge density and $L(\mathbf{r})=-\frac{1}{4} \nabla^{2} \rho(\mathbf{r})$ function has been performed in the framework of the QTAIM. ${ }^{21-23}$ The calculations were performed with the electron density obtained at B3LYP/6-311G(d,p) level using the MP2/aug-ccpVTZ geometries, with the AIM2000 ${ }^{24}$ and AIMAll programs. ${ }^{25}$ QTAIM study was performed at B3LYP/6-311G(d,p) level to analyze the electron density of the systems using a full electron description in all cases.

\section{Results and discussion}

\subsection{Geometric and energetic parameters}

The geometric and energetic parameters of the XBs complexes studied are listed in Table 1 . The fully optimized geometries show a non-linear arrangement (see Fig. 2), with bond angles $\mathrm{Br} \cdots \mathrm{X}-\mathrm{R}$ between $92.5^{\circ}$ and $116.2^{\circ}$, while the angle $\mathrm{F}-\mathrm{Br} \cdots \mathrm{X}$ is always close to 180 degrees. According to Murray-Rust et al., ${ }^{26,27}$ the $\mathrm{F}-\mathrm{Br}$ molecule acts as electron acceptor (Lewis acid) and the $\mathrm{X}-\mathrm{R}$ molecule as electron donor (Lewis base). In all cases, the intermolecular equilibrium distances $\mathrm{Br} \cdots \mathrm{X}$ are shorter than the sum of the van der Waals radii ${ }^{28}$ of the interacting atoms $\left[r_{\mathrm{vdw}}(\mathrm{Br})+r_{\mathrm{vdw}}(\mathrm{X})\right]$. This indicates that the $\mathrm{Br} \cdots \mathrm{X}$ interactions are stabilizing, even when the two interacting atoms bear a partial positive charge, as in the $\mathrm{F}-\mathrm{Br}^{\delta+} \ldots{ }^{\delta+} \mathrm{Cl}-\mathrm{F}, \mathrm{F}-\mathrm{Br}^{\delta+} \ldots{ }^{\delta+} \mathrm{Br}-\mathrm{F}$ and $\mathrm{F}-\mathrm{Br}^{\delta+} \ldots{ }^{\delta+} \mathrm{I}-\mathrm{F}$ complexes.

The $\mathrm{Br} \cdots \mathrm{X}$ intermolecular distances ranges from 2.695 to $3.082 \AA$. These values are in line with the values reported by Alkorta et al. performed at the same level of calculation for the complexes $\mathrm{F}-\mathrm{Br} \cdots \mathrm{F}-\mathrm{Br}(2.686 \AA)$ and $\mathrm{Cl}-\mathrm{Br} \cdots \mathrm{Cl}-\mathrm{Br}(3.152 \AA)^{29}$ and those reported by Wang et al. $\mathrm{F}-\mathrm{Br} \cdots \mathrm{F}-\mathrm{Br}(2.719 \AA)$, $\mathrm{F}-\mathrm{Br} \cdots \mathrm{Br}-\mathrm{F}(3.170 \AA)$ and $\mathrm{F}-\mathrm{Br} \cdot \mathrm{Br}-\mathrm{H}(3.143 \AA)$ complexes calculated at MP2/aug-cc-pVDZ level. The Br $\cdots \mathrm{X}$ intermolecular distances in the $\mathrm{F}-\mathrm{Br} \cdot \mathrm{X}-\mathrm{H}$ complexes increase in the order $\mathrm{Br} \cdots \mathrm{F}<\mathrm{Br} \cdots \mathrm{Cl}<\mathrm{Br} \cdots \mathrm{Br}<\mathrm{Br} \cdots \mathrm{I}$. This is consistent with the relative size of the electron donor halogen atom, which increases from fluorine to iodine. ${ }^{28}$ However, in the $\mathrm{F}-\mathrm{Br} \cdots \mathrm{X}-\mathrm{F}$ complexes the variation of this distance does not show the same trend, being $\mathrm{Br} \cdots \mathrm{F}<\mathrm{Br} \cdots \mathrm{Br} \approx \mathrm{Br} \cdots \mathrm{Cl} \approx \mathrm{Br} \cdots \mathrm{I}$.

The variation of the $\mathrm{F}-\mathrm{Br}$ distances due to the complexation, $\Delta d(\mathrm{~F}-\mathrm{Br})$, are listed in Table 1 . In all cases, an elongation of the $\mathrm{F}-\mathrm{Br}$ distance is observed (positive value of $\Delta d(\mathrm{~F}-\mathrm{Br})$ ) as in the so-called proper hydrogen bonds. This variation ranges between $0.002 \AA$ in the F-Br $\cdots$ F-F complex to $0.032 \AA$ in the F-Br $\cdots$ I-F one.

The total interaction energies of the $\mathrm{F}-\mathrm{Br} \cdots \mathrm{X}-\mathrm{R}$ complexes range from $-1.5 \mathrm{kcal} \mathrm{mol}^{-1}$ (for the $\mathrm{F}-\mathrm{Br} \cdots \mathrm{F}-\mathrm{F}$ complex) to $-6.3 \mathrm{kcal} \mathrm{mol}^{-1}$ (for $\mathrm{F}-\mathrm{Br} \cdot \mathrm{I}-\mathrm{H}$ complex). These values are in the same order of magnitude as the ones reported by Alkorta et al. for the $\mathrm{F}-\mathrm{Br} \cdots \mathrm{F}-\mathrm{Br}\left(-3.7 \mathrm{kcal} \mathrm{mol}^{-1}\right)$ and $\mathrm{Cl}-\mathrm{Br} \cdots \mathrm{Cl}-\mathrm{Br}(-3.5 \mathrm{kcal}$ $\mathrm{mol}^{-1}$ ) interactions obtained at MP2/aug-cc-pVTZ level of theory. ${ }^{29}$ They are also consistent with the interaction energies reported by Wang et al. for the $\mathrm{F}-\mathrm{Br} \cdots \mathrm{F}-\mathrm{Br}\left(-3.0 \mathrm{kcal} \mathrm{mol}{ }^{-1}\right), \mathrm{F}-\mathrm{Br} \cdots \mathrm{Br}-\mathrm{F}$ $\left(-2.7 \mathrm{kcal} \mathrm{mol}^{-1}\right)$ and $\mathrm{F}-\mathrm{Br} \cdot \mathrm{Br}-\mathrm{H}\left(-4.0 \mathrm{kcal} \mathrm{mol}^{-1}\right)$ calculated at $\operatorname{CCSD}(\mathrm{T}) /$ aug-cc-pVDZ level. It is also important to note that the strength of the interactions $\mathrm{F}-\mathrm{Br} \cdots \mathrm{X}-\mathrm{H}$ varies with the electron donor-X, increasing (in absolute value) in the order $\mathrm{F}-\mathrm{Br} \cdots \mathrm{F}-\mathrm{H}<$ $\mathrm{F}-\mathrm{Br} \cdots \mathrm{Cl}-\mathrm{H}<\mathrm{F}-\mathrm{Br} \cdots \mathrm{Br}-\mathrm{H}<\mathrm{F}-\mathrm{Br} \cdots \mathrm{I}-\mathrm{H}$. The same trend is observed for the $\mathrm{F}-\mathrm{Br} \cdots \mathrm{X}-\mathrm{F}$ interactions. These remarks agree with the polarizability of the halogen atoms which increases in the order $\mathrm{F}<\mathrm{Cl}<\mathrm{Br}<\mathrm{I}$. However, from intuition based on the difference in electronegativity between the atoms of the electron donor molecule, $\mathrm{X}-\mathrm{R}$, an inverse order in the interaction energies 
Table 1 Selected geometric parameters, sum of van der Waals radii of the bromine and electron donor-X halogen atoms and binding energies

\begin{tabular}{|c|c|c|c|c|c|c|}
\hline Complexes & $d(\mathrm{Br} \cdots \mathrm{X})$ & $r_{\mathrm{vdw}}(\mathrm{Br})+r_{\mathrm{vdw}}(\mathrm{X})$ & $\Delta d(\mathrm{~F}-\mathrm{Br})$ & $\angle \mathrm{Br} \cdots \mathrm{X}-\mathrm{D}$ & $\angle \mathrm{F}-\mathrm{Br} \cdots \mathrm{X}$ & $E_{\text {Bind }}$ \\
\hline $\mathrm{FBr} \cdots \mathrm{FF}$ & 2.873 & & 0.002 & 103.2 & 177.1 & -1.5 \\
\hline $\mathrm{FBr} \cdots \mathrm{ClH}$ & 2.977 & 3.60 & 0.012 & 93.5 & 179.0 & -3.9 \\
\hline $\mathrm{FBr} \cdots \mathrm{BrH}$ & 3.019 & 3.70 & 0.017 & 93.1 & 179.7 & -5.0 \\
\hline $\mathrm{FBr} \cdots \mathrm{BrF}$ & 2.993 & & 0.014 & 99.2 & 179.5 & -4.0 \\
\hline $\mathrm{FBr} \cdots \mathrm{IH}$ & 3.082 & 3.83 & 0.029 & 92.5 & 179.9 & -6.3 \\
\hline
\end{tabular}

$d(\mathrm{Br} \cdots \mathrm{X})$ : intermolecular distance. $r_{\mathrm{vdw}}(\mathrm{Br})+r_{\mathrm{vdw}}(\mathrm{X})$ : sum of the van der Waals radii of $\mathrm{Br}$ and electron donor-X atoms. $\Delta d(\mathrm{~F}-\mathrm{Br}):$ is the change of $\mathrm{F}-\mathrm{Br}$ bond length upon complex formation. $\angle \mathrm{Br} \cdots \mathrm{X}-\mathrm{D}$ and $\angle \mathrm{F}-\mathrm{Br} \cdots \mathrm{X}$ : bond angles. $E_{\mathrm{Bind}}$ : binding energy calculated at CCSD(T)/CBS. Distances

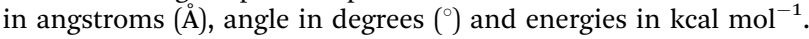

would be expected since the charge of the halogen atom in the $\mathrm{X}-\mathrm{H}$ molecule should be $\mathrm{I}<\mathrm{Br}<\mathrm{Cl}<\mathrm{F}$ from which the binding energies follow. Something similar is observed when considering the $\mathrm{X}-\mathrm{F}$ molecules.

Moreover, the binding energy of the $\mathrm{F}-\mathrm{Br} \cdots \mathrm{X}-\mathrm{H}$ complexes is greater than for the $\mathrm{F}-\mathrm{Br} \cdots \mathrm{X}-\mathrm{F}$ complexes, for the same electron donor-X. This could be due to the strong inductive effect exerted by the fluorine on the electronic cloud of the electron donor-X, leaving it with a partial positive charge, resulting in a decreased nucleophilic ability of this atom. It is expected that this effect (decrease of the nucleophilic ability of the electron donor- $\mathrm{X}$ when going from $\mathrm{X}-\mathrm{H}$ to $\mathrm{X}-\mathrm{F}$ ) will be intensified as we go down the halogen group in the periodic table, since the difference of electronegativity increases between the atoms of the electron donor group (X-F). However, this does not happen, and the binding energy of the $\mathrm{F}-\mathrm{Br} \cdots \mathrm{F}-\mathrm{F}$ complex is $58 \%$ lower than the binding energy of the $\mathrm{F}-\mathrm{Br} \cdots \mathrm{F}-\mathrm{H}$ complex, the binding energy of the $\mathrm{F}-\mathrm{Br} \cdots \mathrm{Cl}-\mathrm{F}$ complex is $30 \%$ lower than the binding energy of the $\mathrm{F}-\mathrm{Br} \cdots \mathrm{Cl}-\mathrm{H}$ complex, the binding energy of the $\mathrm{F}-\mathrm{Br} \cdots \mathrm{Br}-\mathrm{F}$ complex is $19 \%$ lower than the binding energy of the $\mathrm{F}-\mathrm{Br} \cdots \mathrm{Br}-\mathrm{H}$ complex and the binding energy of the $\mathrm{F}-\mathrm{Br} \cdots \mathrm{I}-\mathrm{F}$ complex is $4 \%$ lower than the binding energy of the $\mathrm{F}-\mathrm{Br} \cdots \mathrm{I}-\mathrm{H}$ complex. Therefore, the relative effect that fluorine produces over the donor capacity of the electrons (Lewis base) of electron donor- $\mathrm{X}$ halogen in $\mathrm{X}-\mathrm{F}$ molecules decreases in the order $\mathrm{F}>\mathrm{Cl}>\mathrm{Br}>\mathrm{I}$.

These results allow us to establish that the differences in electronegativity between the atoms of the electron donor molecules do not play a fundamental role in the stabilization of these complexes. In addition, it appears that the polarizability of the electron donor-X halogen plays a key role in stabilizing these halogen bonding interactions. Therefore, we believe that a deeper electronic analysis is needed to understand the physical nature of these interactions.

\subsection{Molecular electrostatic potentials}

The molecular electrostatic potential (MEP) is a powerful tool that has been used to explain many properties of the $\mathrm{XBs}^{2,6}$ and other similar interactions. ${ }^{3,30}$ According to Politzer et al. the features and properties of the XBs "can be fully explained in terms of electrostatics and polarization plus dispersion. The strengths of the interactions generally correlate well with the values of the electrostatic potential maximum or $\sigma$-hole (Lewis
Table 2 Minimum $\left(V_{S, \text { min }}\right)$ electrostatic potentials on the 0.001 a.u. electron density isosurface around the $X$ atom

\begin{tabular}{lr}
\hline Molecule R-X & $V_{\mathrm{S}, \min }$ \\
\hline $\mathrm{H}-\mathrm{F}$ & -25.3 \\
$\mathrm{~F}-\mathrm{F}$ & -2.7 \\
$\mathrm{H}-\mathrm{Cl}$ & -10.6 \\
F-Cl & -0.1 \\
$\mathrm{H}-\mathrm{Br}$ & -9.4 \\
F-Br & -0.5 \\
$\mathrm{H}-\mathrm{I}$ & -7.5 \\
F-I & 0.2
\end{tabular}

$V_{\mathrm{S}, \mathrm{min}}:$ reflect the lone pairs of the electron donor-X. All values in $\mathrm{kcal} \mathrm{mol}^{-1}$.

acid) and minimum (Lewis base) usually associated to the lone pairs. However, in certain instances, polarizabilities must be taken into account explicitly, as the polarization of the negative site reaches a level that can be viewed as a degree of dative sharing (coordinate covalence)". ${ }^{3}$ Table 2 reports the most negative potentials on the 0.001 a.u. electron density isosurface, $V_{\mathrm{S}, \mathrm{min}}$, around the electron donor halogen atom, $\mathrm{X}$.

The results, as shown in Table 2, apparently indicate that these interactions can be understood in terms of the electrostatic attraction between the positive $\sigma$-hole of the $\mathrm{Br}$ atom and a negative site of the electron donor-X halogen atom (lone pairs). The negative site of the electron donor-X atom in $\mathrm{X}-\mathrm{H}$ molecule is greater than in the $\mathrm{X}-\mathrm{F}$ molecule, for the same electron donor- $\mathrm{X}$, in accordance with the binding energies of the $\mathrm{F}-\mathrm{Br} \cdots \mathrm{X}-\mathrm{H}$ and $\mathrm{F}-\mathrm{Br} \cdots \mathrm{X}-\mathrm{F}$ complexes. That is, these complexes are electrostatic in nature. However, further analysis reveals that if only the electrostatic potentials of the isolated monomers are considered, they are not sufficient to explain the energetic results obtained. For instance, the $V_{\mathrm{S}, \min }$ of the F-F molecule is $89 \%$ lower than the one in the $\mathrm{F}-\mathrm{H}$ molecule, while the binding energy of the $\mathrm{F}-\mathrm{Br} \cdots \mathrm{F}-\mathrm{F}$ complex is $58 \%$ lower than the one in the $\mathrm{F}-\mathrm{Br} \cdots \mathrm{F}-\mathrm{H}$ complex. This difference is even more dramatic when the size of the $\mathrm{X}$ atom increases. As expected from the previous discussion, no correlation is found between the values of $V_{\mathrm{S}, \min }$ and $E_{\mathrm{Bind}}$. Therefore, it is clear that to understand the nature of these interactions a deeper electronic analysis is necessary.

\subsection{Molecular polarizability}

The electron polarizability is a measure of the response offered by the molecular system to the disturbance produced by an electric field. When the disturbance is caused by a weak electric 


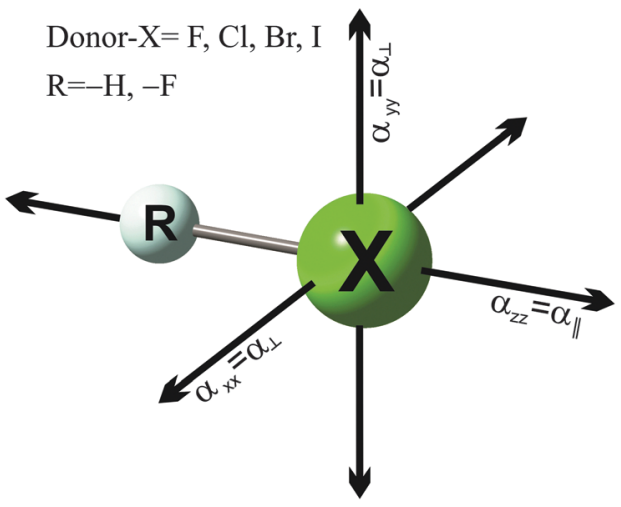

Fig. 1 Main axes of polarizability.

field (as produced by an atom of a molecule with a partial positive charge), the induced dipole moment $\left(\mu_{\text {ind }}\right)$ by the electric field $E$ is given by $\mu_{\text {ind }}=\alpha \cdot E$, where $\alpha$ is the polarizability tensor.

In linear molecules, there are only two independent components of the polarizability: $\alpha_{z z}$, also known as parallel polarizability, $\alpha_{\|}$, measured in the direction of the main axis of polarizability, is matched with the main axis of symmetry of the molecules. The other two components, measured in the perpendicular direction $\left(\alpha_{x x}\right.$ and $\left.\alpha_{y y}\right)$, also called perpendicular polarizability, $\alpha_{\perp}$, are identical in the present case. Fig. 1 shows the main axes of polarizability for the X-R molecules, where it is observed that the origin of the coordinates is situated practically on the nucleus of the electron donor-X halogen atom. The values of $\alpha_{x x}$ and $\alpha_{y y}$ will give us a direct measure of the deformation capacity of the electron density of the $\mathrm{X}$ halogen in the equatorial direction of the $\sigma_{\mathrm{X}-\mathrm{R}}$ bond, where the lone pairs of the electron donor- $\mathrm{X}$ atom are approximately located. However, in the $\mathrm{F}_{2}$ molecule these axes are in the center of the $\sigma_{\mathrm{F}-\mathrm{F}}$ bond, in this case the measure of the polarizability in these directions $\left(\alpha_{x x}\right.$ and $\left.\alpha_{y y}\right)$ can not be associated with the deformation capacity of the lone pairs of the fluorine atom.

Table 3 reports polarizability (perpendicular, $\alpha_{\perp} ;$ parallel, $\alpha_{\|}$; spherical, $\left.\alpha_{\mathrm{s}}\right)$ and anisotropy of the polarizability $(\Delta \alpha)$ of the electron donor molecules, X-R. It is observed that $\alpha_{\perp}, \alpha_{\|}$and $\alpha_{\mathrm{s}}$ of the electron donor- $\mathrm{X}-\mathrm{H}$ molecules increase in the order $\mathrm{F}-\mathrm{H}<\mathrm{Cl}-\mathrm{H}<\mathrm{Br}-\mathrm{H}<\mathrm{I}-\mathrm{H}$. Something similar is observed

Table 3 Molecular polarizabilities, calculated at MP2/aug-cc-pVTZ (MP2/ def2-TZVPP for iodine) computational level. The anisotropic polarizability is also included

\begin{tabular}{lllll}
\hline Molecule & $\alpha_{\perp}$ & $\alpha_{\|}$ & $\alpha_{\mathrm{s}}$ & $\Delta \alpha$ \\
\hline FH & 0.734 & 0.944 & 0.804 & 0.148 \\
FF & 0.909 & 1.658 & 1.159 & 0.530 \\
ClH & 2.439 & 2.699 & 2.526 & 0.184 \\
ClF & 2.325 & 3.314 & 2.655 & 0.699 \\
BrH & 3.386 & 3.669 & 3.480 & 0.201 \\
BrF & 3.165 & 4.184 & 3.504 & 0.721 \\
IH & 5.133 & 5.444 & 5.237 & 0.220 \\
IF & 4.781 & 5.657 & 5.073 & 0.620
\end{tabular}

$\alpha_{\perp}$ : perpendicular polarizability. $\alpha_{\|}$: parallel polarizability. $\alpha_{s}$ : spherical polarizability, $\alpha_{\mathrm{s}}=\left(2 \alpha_{\perp}+\alpha_{\|}\right) / 3 . \Delta \alpha$ : anisotropy of the polarizability, $\Delta \alpha=\left\{2\left[\left(2 \alpha_{\perp}-\alpha_{\|}\right)^{2}\right]^{1 / 2}\right\} / 2$. All values in $\AA^{3}$. with the X-F molecules. It is important to note that the binding energies of these complexes increase in the same order. Good linear correlations have been found between the binding energies and polarizabilities $\alpha_{\perp}, \alpha_{\|}$and $\alpha_{s}$. (see Fig. S1 of the ESI $\dagger$ ).

It is important to note that, when replacing $\mathrm{H}$ by $\mathrm{F}$ in the hydrogen halides $(\mathrm{X}-\mathrm{H}), \alpha_{\perp}$ decreases (except for $\mathrm{F}_{2}$ ). This indicates that the lone pairs of the electron donor-X of the $\mathrm{X}-\mathrm{F}$ molecules are less polarizable than the lone pairs of the electron donor- $\mathrm{X}$ of the $\mathrm{X}-\mathrm{H}$ molecules, and so the strength of the $\mathrm{F}-\mathrm{Br} \cdots \mathrm{X}-\mathrm{F}$ interactions is less than for $\mathrm{F}-\mathrm{Br} \cdots \mathrm{X}-\mathrm{H}$ interactions, for a same electron donor-X (see Table 1). Therefore, the nucleophilicity of these molecules depends on the ability of polarization of the lone pairs of the electron donor-X.

These results agree with those published by Wang et al. ${ }^{10}$ for $\mathrm{Br}^{\delta+} \ldots{ }^{\delta+} \mathrm{Br}$ and $\mathrm{H}^{\delta+} \ldots{ }^{\delta+} \mathrm{Br}$ interactions. These authors attribute the stability of these interactions to the large contribution of the dispersion energy (formation of instantaneous multipoles). In this sense, we can think that the polarizability is a measure of the fluctuation of charge in a molecule, so that the instantaneous multipoles can be related to the polarizabilities. Consequently the greater the $\alpha_{\perp}$ of the X-R molecules, the stronger will their interaction by dispersion be.

Based on the foregoing discussion, we can affirm that the deformation capacity of the electronic cloud of the lone pairs of the electron donor-X is very important in stabilizing the $\mathrm{F}-\mathrm{Br} \cdots \mathrm{X}-\mathrm{R}$ complexes.

\subsection{Local topological properties}

The topological analysis the electron density has proved a useful tool to investigate the electronic properties of XBs. ${ }^{31-37}$ Fig. 2 shows the molecular graph and the integrated atomic charges of complexes studied in this work. From the standpoint of the QTAIM, the presence of a bond path is a universal indicator of the existence of a bonding interaction. ${ }^{38} \mathrm{An}$ atomic interaction line of maximum electron density connecting the bridge atom $(\mathrm{Br})$ of the Lewis acid with the electron donor-X halogen atom of the X-R molecules is observed in all cases, confirming that these atoms are chemically bonded.

Table 4 gathers the values of the local topological properties, measured at $\mathrm{Br} \cdots \mathrm{X}$ bond critical points, BCPs. The values of the electron density ranges from 0.0114 to 0.0320 a.u., which is within the value limits commonly accepted for hydrogen bonds ( 0.002 to 0.035 a.u.) and is also consistent with the values reported for similar interactions 0.024 a.u. $(\mathrm{F}-\mathrm{Br} \cdots \mathrm{Br}-\mathrm{F}),{ }^{37}$ 0.014 a.u. $(\mathrm{F}-\mathrm{Br} \cdots \mathrm{F}-\mathrm{Br})$ and 0.008 a.u. $(\mathrm{Cl}-\mathrm{Br} \cdots \mathrm{Cl}-\mathrm{Br}){ }^{28}{ }^{28}$ Moreover, in all cases the sign of $\nabla^{2} \rho\left(\mathbf{r}_{\mathrm{b}}\right)>0$ and the relationship $\lambda_{1} / \lambda_{3}<1$ indicate that they are closed-shell interactions. ${ }^{38}$

It has been proposed that the values of electron density and Laplacian at the BCPs of the hydrogen bonds, HBs, should be used as good indicators of their strength. In previous studies ${ }^{39,40}$ it has been found that the topological properties at the BCP of a molecular interaction reflect the strength of interaction more effectively than other parameters, for example, the geometric parameters. Consequently, we have explored the relationship between the strength of different bonds and topological characteristics at the intermolecular BCP. Thus, when the interaction energy of 


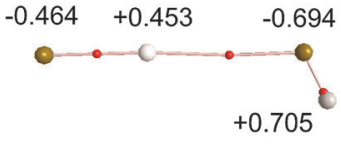

(a)
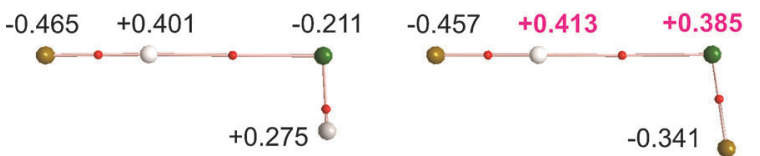

(c)

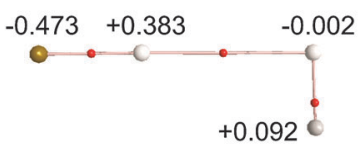

(e)

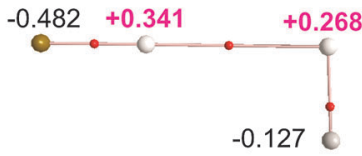

(g)
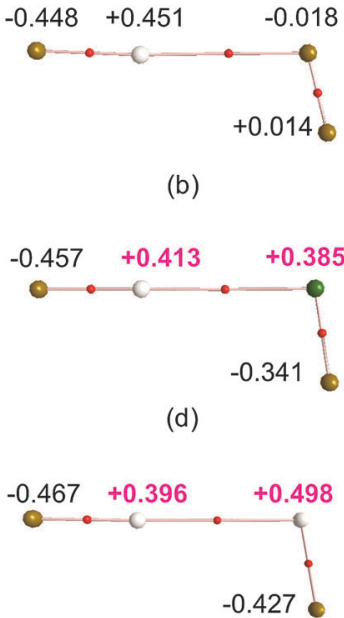

(b)

(d)

(f)

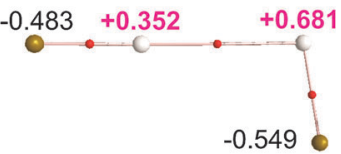

(h)
Fig. 2 Molecular graphs and integrated atomic charges for (a) $\mathrm{FBr} \ldots \mathrm{FH}$, (b) $\mathrm{FBr} \cdots \mathrm{FF}$, (c) $\mathrm{FBr} \cdots \mathrm{ClH}$, (d) $\mathrm{FBr} \cdots \mathrm{ClF}$, (e) $\mathrm{FBr} \cdots \mathrm{BrH}$, (f) $\mathrm{FBr} \cdots \mathrm{BrF}$, (g) $\mathrm{FBr} \ldots \mathrm{IH}$ and (h) $\mathrm{FBr} \ldots \mathrm{IF}$ complexes. The lines connecting the nuclei are the bond paths. Red dots represent BCPs $(3,-1)$. The charges corresponding to interactions between positively charged atoms are indicated in red.

Table 4 Local topological properties of the electron charge density at the intermolecular $\mathrm{Br}$...X BCP

\begin{tabular}{|c|c|c|c|c|}
\hline Complexes & $\rho\left(\mathbf{r}_{\mathrm{b}}\right)$ & $\nabla^{2} \rho\left(\mathbf{r}_{\mathrm{b}}\right)$ & $\left|\lambda_{1}\right| / \lambda_{3}$ & $H\left(\mathbf{r}_{\mathrm{b}}\right)$ \\
\hline $\mathrm{FBr} \cdots \mathrm{FH}$ & 0.0178 & 0.0707 & 0.1470 & 0.0013 \\
\hline $\mathrm{FBr} \cdots \mathrm{FF}$ & 0.0114 & 0.0494 & 0.1360 & 0.0014 \\
\hline $\mathrm{FBr} \cdots \mathrm{ClH}$ & 0.0184 & 0.0648 & 0.1404 & 0.0023 \\
\hline FBr $\cdots \mathrm{ClF}$ & 0.0175 & 0.0647 & 0.1383 & 0.0026 \\
\hline $\mathrm{FBr} \cdots \mathrm{BrH}$ & 0.0169 & 0.0513 & 0.1483 & 0.0017 \\
\hline FBr $\cdots$ BrF & 0.0156 & 0.0504 & 0.1437 & 0.0020 \\
\hline FBr $\cdots$ IH & 0.0264 & 0.0583 & 0.1863 & -0.0002 \\
\hline FBr $\cdots$ IF & 0.0320 & 0.0657 & 0.2016 & -0.0015 \\
\hline
\end{tabular}

$\rho\left(\mathbf{r}_{\mathrm{b}}\right)$ : electron density. $\nabla^{2} \rho\left(\mathbf{r}_{\mathrm{b}}\right)$ : Laplacian of electron density. $H\left(\mathbf{r}_{\mathrm{b}}\right)$ : total energy density. All values in atomic units except $\left|\lambda_{1}\right| / \lambda_{3}$ that is dimensionless.

the $\mathrm{F}-\mathrm{Br} \cdot \mathrm{X}-\mathrm{X}$ complexes with the same electron donor-X are compared, it is observed that the strength is correlated with the electron density at the BCP. For example, the electron density at the $\mathrm{BCP}$ in the $\mathrm{F}-\mathrm{Br} \cdot \mathrm{F}-\mathrm{H}$ complex is greater than the one in the $\mathrm{F}-\mathrm{Br} \cdots \mathrm{F}-\mathrm{F}$ one. The same is observed in complexes where the electron donor-X is $\mathrm{Cl}$ or $\mathrm{Br}$. However in the $\mathrm{F}-\mathrm{Br} \cdots \mathrm{I}-\mathrm{F}$ complexes, the opposite occurs. Accordingly, the comparison of the stabilization energy with the electron density at the BCP, in these XBs, should be restricted to complex structures in which the pair of interacting atoms is always the same, except when electron donor-X is iodine atom.

It has been established in numerous investigations that the values of the total energy density, $H\left(\mathbf{r}_{\mathrm{b}}\right)$ and of the $\nabla^{2} \rho\left(\mathbf{r}_{\mathrm{b}}\right)$ at the BCP allow the interaction to be characterised. ${ }^{41-43} H\left(\mathbf{r}_{\mathrm{b}}\right)<0$ and $\nabla^{2} \rho\left(\mathbf{r}_{\mathrm{b}}\right)<0$ indicate an accumulation of charge density at BCP and therefore a covalent interaction between the interacting atoms. $H\left(\mathbf{r}_{\mathrm{b}}\right)>0$ is always indicative of closed-shell interactions $\left[\nabla^{2} \rho\left(\mathbf{r}_{\mathrm{b}}\right)>0\right]$. An interesting situation occurs when $H\left(\mathbf{r}_{\mathrm{b}}\right)<0$ but $\nabla^{2} \rho\left(\mathbf{r}_{\mathrm{b}}\right)>0$. It has been postulated for such cases that the $\mathrm{HB}$ interaction has a partially covalent character. ${ }^{41,44}$ However, the current meaning of $H\left(\mathbf{r}_{\mathrm{b}}\right)$ as a descriptor of the covalency of the $\mathrm{HB}$ and $\mathrm{XB}$ interactions has been strongly disputed. We recently found that the decrease of $H\left(\mathbf{r}_{\mathrm{b}}\right)$ with increasing $\rho\left(\mathbf{r}_{\mathrm{b}}\right)$ could be considered as an indicator of the strengthening or stabilization of the interaction, in the same way as the decrease in the interaction energy is an indicator of the complex stabilization. Consequently, a negative value of $H\left(\mathbf{r}_{\mathrm{b}}\right)$ (or its trend towards negative values) is not necessarily associated with the covalency of the interaction. ${ }^{45-47}$ In other words, the decrease of $H\left(\mathbf{r}_{\mathrm{b}}\right)$ with the interaction strengthening is a consequence of the increase in the attractive electrostatic part of the interaction energy rather than the increase in its covalent character, as is commonly considered. In this sense, when we compare $\rho\left(\mathbf{r}_{\mathrm{b}}\right)$ and $H\left(\mathbf{r}_{\mathrm{b}}\right)$ in the $\mathrm{F}-\mathrm{Br} \cdots \mathrm{X}-\mathrm{H}$ complexes $v s$. the $\mathrm{F}-\mathrm{Br} \cdots \mathrm{X}-\mathrm{F}$ ones for the same electron donor-X, it is observed that whenever there is an increase in $\rho\left(\mathbf{r}_{\mathrm{b}}\right)$, a decrease in $H\left(\mathbf{r}_{\mathrm{b}}\right)$ is observed. In other words, $\rho\left(\mathbf{r}_{\mathrm{b}}\right)$ at the BCP of the $\mathrm{F}-\mathrm{Br} \cdots \mathrm{F}-\mathrm{H}$ complex is greater than the F-Br $\cdots \mathrm{F}-\mathrm{F}$ complex and $H\left(\mathbf{r}_{\mathrm{b}}\right)$ of the $\mathrm{F}-\mathrm{Br} \cdots \mathrm{F}-\mathrm{H}$ complex is lower than the $\mathrm{F}-\mathrm{Br} \cdots \mathrm{F}-\mathrm{F}$ complex, and the same applies to the complexes where the electron donor- $\mathrm{X}$ is $\mathrm{Cl}$ or $\mathrm{Br}$, while for the iodine atom the electron density at the $\mathrm{Br} \cdots \mathrm{I}$ BCP is greater and $H\left(\mathbf{r}_{\mathrm{b}}\right)$ is lower in the $\mathrm{F}-\mathrm{Br} \cdots \mathrm{I}-\mathrm{F}$ complex. In this context, we can say that the electrostatic interaction in the $\mathrm{F}-\mathrm{Br} \cdots \mathrm{X}-\mathrm{H}$ complexes is greater than in the $\mathrm{F}-\mathrm{Br} \cdots \mathrm{X}-\mathrm{F}$ complexes, for the same electron donor-X (where $\mathrm{X}=\mathrm{F}, \mathrm{Cl}, \mathrm{Br}$ ), while for electron donor-X $=\mathrm{I}$ the electrostatic interaction is greater in the $\mathrm{F}-\mathrm{Br} \cdots \mathrm{I}-\mathrm{F}$ complex.

\subsection{Integrated topological properties}

The integration of electron density on the atomic basins provides a useful tool for analyzing atomic charges, $q(\Omega)$, electron charge transfer, $\Delta N(\Omega)$ and the quadrupole moments, $Q(\Omega)$. These values are reported in Fig. 2 and Table 5.

3.5.1. Atomic charges. The values of the calculated atomic charges confirm that the interactions $\mathrm{F}-\mathrm{Br} \cdot \mathrm{X}-\mathrm{F}$ occur between positively charged atoms, $\mathrm{Br}^{\delta+} \ldots{ }^{\delta+} \mathrm{X}$, (see Fig. 2) except in the $\mathrm{F}-\mathrm{Br} \cdots \mathrm{F}-\mathrm{F}$ complex. The product of the positive charges of these interacting atoms, increased in the order $\mathrm{F}-\mathrm{Br} \cdots \mathrm{Cl}-\mathrm{F}<$ $\mathrm{F}-\mathrm{Br} \cdots \mathrm{Br}-\mathrm{F}<\mathrm{F}-\mathrm{Br} \cdots \mathrm{I}-\mathrm{F}$ giving values of $q\left(\Omega_{\mathrm{Br}}\right) \times q\left(\Omega_{\mathrm{Cl}}\right)=$ $0.159 e^{2}, q\left(\Omega_{\mathrm{Br}}\right) \times q\left(\Omega_{\mathrm{Br}}\right)=0.197 e^{2}$ and $q\left(\Omega_{\mathrm{Br}}\right) \times q\left(\Omega_{\mathrm{I}}\right)=0.239 e^{2}$ respectively. It is expected that repulsive electrostatic interactions will increase in this order and therefore the stability of the complexes decreases. However, as noted in the discussion of the binding energies, the $\mathrm{F}-\mathrm{Br} \cdots \mathrm{X}-\mathrm{F}$ complexes are more stable as the size of $\mathrm{X}$ increases. This result is not surprising, because it has been highlighted that many covalently bonded atoms cannot be represented adequately by a single charge due to the anisotropy of the charge distribution. ${ }^{48}$ According to Politzer et al. these interactions could not be understood in terms of atomic charges assigned by any of the usual procedures, which view a bonded atom as being entirely positive or negative. ${ }^{49}$ 
Table 5 Charge transfer and atomic quadrupole moment of electron donor-X (parallel and perpendicular components). The change in the perpendicular component of the quadrupole moment with respect to that in the isolated monomers is also included

\begin{tabular}{lllll}
\hline Complexes & $\Delta N_{(\mathrm{X}-\mathrm{R})}$ & $Q_{\|}\left(\Omega_{\mathrm{X}}\right)$ & $Q_{\perp}\left(\Omega_{\mathrm{X}}\right)$ & $\Delta Q_{\perp}\left(\Omega_{\mathrm{X}}\right)$ \\
\hline FBr $\cdots$ FH & 0.011 & 8.617 & $-0.104(-0.085)$ & 0.019 \\
FBr $\cdots$ FF & 0.000 & 8.144 & $-0.900(-0.895)$ & 0.005 \\
FBr $\cdots$ ClH & 0.064 & 8.482 & $-2.366(-1.923)$ & 0.442 \\
FBr $\cdots$ ClF & 0.044 & 8.062 & $-3.501(-3.149)$ & 0.353 \\
FBr $\cdots$ BrH & 0.090 & 8.508 & $-3.421(-2.869)$ & 0.552 \\
FBr $\cdots$ BrF & 0.070 & 8.280 & $-4.473(-4.001)$ & 0.472 \\
FBr $\cdots$ IH & 0.141 & 8.450 & $-5.600(-4.565)$ & 1.035 \\
FBr $\cdots$ IF & 0.132 & 8.262 & $-6.645(-5.659)$ & 0.986
\end{tabular}

$\Delta N_{(\mathrm{X}-\mathrm{R})}$ : charge transfer from the XR electron donor to the FBr electron acceptor. $\Delta N_{(\mathrm{X}-\mathrm{D})}$ were calculated as the difference between the sum of the atomic population in all atoms in the isolated base $(\mathrm{X}-\mathrm{R})$ and the same sum in the complex. $Q_{\|}\left(\Omega_{\mathrm{Br}}\right)$ : parallel component of the atomic quadrupole moment of the $\mathrm{Br}$ atom of the $\mathrm{FBr}$ molecule. $Q_{\|}\left(\Omega_{\mathrm{Br}}\right)_{\mathrm{F}-\mathrm{Br} \text { isolated }}=8.002$. $Q_{\perp}\left(\Omega_{\mathrm{X}}\right)$ : perpendicular component of the atomic quadrupole moment of the electron donor-X halogen atom in the complex and in the isolated monomer are given in parentheses. $\Delta Q_{\perp}\left(\Omega_{\mathrm{X}}\right)$ : variation of the perpendicular component of the atomic quadrupole moment. It was calculated subtracting the property value of the atom in the isolated compound to the value of the corresponding property in the complex. All quantities in atomic units.

3.5.2. Electron charge transfer. In most cases (except in $\mathrm{F}-\mathrm{Br} \cdots \mathrm{F}-\mathrm{F}$ ), a net transfer of charge occurs from the electron donor molecule, $\mathrm{X}-\mathrm{R}$ (Lewis base) to the electron acceptor molecule, $\mathrm{F}-\mathrm{Br}$ (Lewis acid). In the $\mathrm{F}-\mathrm{Br} \cdots \mathrm{X}-\mathrm{H}$ complexes, the transferred electron density increases in the order in which the strength of interactions increases, i.e. in the order $\mathrm{F}-\mathrm{Br} \cdots \mathrm{F}-\mathrm{H}<$ $\mathrm{F}-\mathrm{Br} \cdots \mathrm{Cl}-\mathrm{H}<\mathrm{F}-\mathrm{Br} \cdots \mathrm{Br}-\mathrm{H}<\mathrm{F}-\mathrm{Br} \cdots \mathrm{I}-\mathrm{H}$. The $\mathrm{F}-\mathrm{Br} \cdots \mathrm{X}-\mathrm{F}$ complexes show the same trend. Furthermore, when we compare the charge transfer, $\Delta N(\mathrm{X}-\mathrm{R})$, in the $\mathrm{F}-\mathrm{Br} \cdots \mathrm{X}-\mathrm{H}$ complexes $v s$. the $\mathrm{F}-\mathrm{Br} \cdots \mathrm{X}-\mathrm{F}$ ones, for the same electron donor-X, it is observed that the charge transfer in the first one is greater than in the second one. These results indicate that, the lone pairs of the electron donor-X in the X-F molecules are less polarizable (see values of $\alpha_{\perp}$ in Table 2) than in the $\mathrm{X}-\mathrm{H}$ ones and therefore the charge transfer contributes significantly to the stability of these interactions.

3.5.3. Quadrupole moment. The atomic quadrupole moment is a measure of the deviation of the electron density from the spherical symmetry. Thus, a diagonal component of the tensor $Q<0$ indicates that the electron density is concentrated along this axis and vice versa. ${ }^{21}$ The quadrupole moment may be useful for studying molecular interactions, particularly in the case of van der Waals weak interactions. Table 4 reports the values of the quadrupole moment determined on the atomic basin of the $\mathrm{Br}$ atom of the $\mathrm{F}-\mathrm{Br}$ Lewis acid, $Q_{\|}\left(\Omega_{\mathrm{Br}}\right)$, measured in the parallel direction to the $\sigma_{\mathrm{F}-\mathrm{Br}}$ bond. In addition, the values of the quadrupole moment determined on the basin of the halogen atoms of the Lewis basis, $Q_{\perp}\left(\Omega_{\mathrm{X}}\right)$, measured in the isolated molecules in the perpendicular direction to the $\sigma_{\mathrm{X}-\mathrm{R}}$ bond and in the complexes in the perpendicular direction to $\sigma_{\mathrm{X}-\mathrm{R}}$ bond and in the direction of the $\mathrm{Br} \cdot \mathrm{X}$ interaction are reported. The value of $Q_{\perp}\left(\Omega_{\mathrm{X}}\right)$ can be taken as a rough indicator of the deformation of the electron density of the lone pairs of the $\mathrm{X}$ halogen in $\mathrm{X}-\mathrm{R}$ molecules. In the isolated $\mathrm{F}-\mathrm{Br}$ molecule, $Q_{\|}\left(\Omega_{\mathrm{Br}}\right)>0\left[Q_{\|}\left(\Omega_{\mathrm{Br}}\right)=8.002\right.$ a.u. $]$ indicating that the distribution of electron density around the $\mathrm{Br}$ atom, with respect to the symmetry axis of the molecule, is oblate. That is, the $\mathrm{Br}$ atom of the $\mathrm{F}-\mathrm{Br}$ molecule has its electron charge concentrated in the equatorial direction. Once the complex is formed, $Q_{\|}\left(\Omega_{\mathrm{Br}}\right)$ becomes more positive (see Table 4), that is, the electronic density of the $\mathrm{Br}$ atom becomes even more oblate. This favors the electrostatic interaction between the nucleus of the $\mathrm{Br}$ atom of the Lewis acid and the electron cloud of the electron donor-X halogen atom of the Lewis basis.

Moreover, $Q_{\perp}\left(\Omega_{\mathrm{X}}\right)<0$ for all the electron donor-X halogen atoms of the electron donor molecules $\mathrm{X}-\mathrm{H}$ and $\mathrm{X}-\mathrm{F}$, which indicates that in this direction there is an accumulation of electron density. In addition, it is observed that $Q_{\perp}\left(\Omega_{\mathrm{X}}\right)$ of the $\mathrm{X}-\mathrm{H}$ molecules follows the order $\mathrm{F}-\mathrm{H}<\mathrm{Cl}-\mathrm{H}<\mathrm{Br}-\mathrm{H}<\mathrm{I}-\mathrm{H}$, which is the same trend as for the $\mathrm{X}-\mathrm{F}$ molecules. That is, these values follow the same order as the values of the binding energies of the $\mathrm{F}-\mathrm{Br} \cdots \mathrm{X}-\mathrm{H}$ and $\mathrm{F}-\mathrm{Br} \cdots \mathrm{X}-\mathrm{F}$ complexes respectively. Even more, good linear relationships between $Q_{\perp}\left(\Omega_{\mathrm{X}}\right)$ and $\Delta E_{\mathrm{MP} 2}$ for $\mathrm{F}-\mathrm{Br} \cdots \mathrm{X}-\mathrm{H}$ and $\mathrm{F}-\mathrm{Br} \cdots \mathrm{X}-\mathrm{F}$ interactions are found (Fig. 3). This indicates that the accumulation of the electron density in the equatorial direction of the electron donor-X, measured by $Q_{\perp}\left(\Omega_{\mathrm{X}}\right)$, is a good indicator of the strength of the interactions studied here.

The values of $Q_{\perp}\left(\Omega_{\mathrm{X}}\right)$ in the complexes are greater in magnitude that in the corresponding isolated molecules. This indicates that as a result of the complex formation a deformation of the electronic cloud of the electron donor- $\mathrm{X}$ in the equatorial direction to the $\sigma_{\mathrm{X}-\mathrm{R}}$ bond occurs. This deformation can be associated with the polarizability of the lone pairs of the electron donor-X. The values of $\Delta Q_{\perp}\left(\Omega_{\mathrm{X}}\right)$ give a measure of the change experienced by the electronic cloud of the electron donor-X due to the complexation. Thus, $\Delta Q_{\perp}\left(\Omega_{\mathrm{X}}\right)$ in the $\mathrm{F}-\mathrm{Br} \cdots \mathrm{X}-\mathrm{H}$ complexes increases in the order $\mathrm{F}-\mathrm{H}<\mathrm{Cl}-\mathrm{H}<\mathrm{Br}-\mathrm{H}<\mathrm{I}-\mathrm{H}$. A similar trend is observed for the $\mathrm{F}-\mathrm{Br} \cdots \mathrm{X}-\mathrm{F}$ complexes. These observations are consistent with increasing the polarizability of the electron donor-X.

\subsection{Laplacian of the electron density}

The QTAIM provides a framework to characterize the charge distribution of the molecular electron density. ${ }^{38,50,51}$ In this

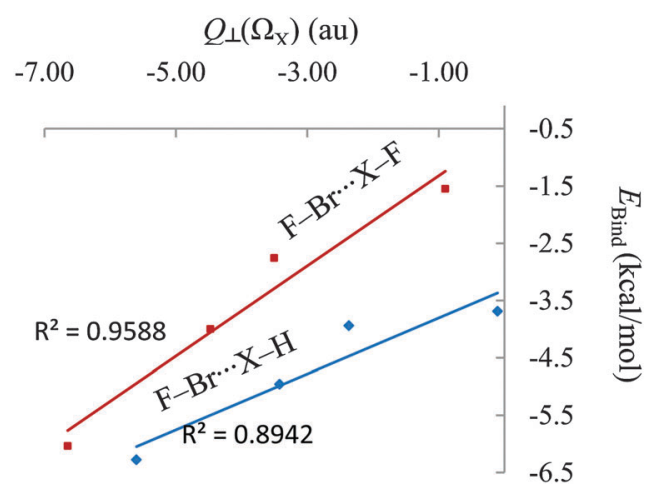

Fig. 3 Correlation between the binding energy and the atomic quadrupole moment of the electron donor $-\mathrm{X}, Q_{\perp}\left(\Omega_{\mathrm{X}}\right)$, measured perpendicular to the $\sigma_{X-R}$ bond and in the direction of the $B r \cdots X$ interaction. 
sense, the topological analysis of its derivative function, $L(\mathbf{r})=-\frac{1}{4} \nabla^{2} \rho(\mathbf{r})$, is an excellent tool to address a deep investigation of the electronic properties of a molecular system, allowing the exploration of interatomic interactions. The topology of $L(\mathbf{r})$ function allows us to identify areas of concentration $[L(\mathbf{r})>0]$ and depletion of electron charge $[L(\mathbf{r})<0]$.

The valence shell of an atom is divided into an inner region where $L(\mathbf{r})>0$ and an outer one where $L(\mathbf{r})<0$. The first one is called the valence shell charge concentration (VSCC). Thus, a local maximum (or minimum) in $L(\mathbf{r})$ signifies a local concentration (or depletion) of electron density.

There are several studies that describe the use of the AIM theory, the valence shell of isolated atoms, ${ }^{21,22,52,53}$ and covalent molecules. ${ }^{21,22}$ Analysis of the Laplacian of the electron charge density in atoms has been shown to reproduce the structure of atomic layers of the first three rows of the periodic table. Similar studies in molecules are consistent with predictions based on the Valence Shell Electron Pair Repulsion (VSEPR) model. ${ }^{54}$ It has also shown that the highest concentration of charge in the valence shell, denoted by CPs $(3,-3)$ in the distribution of $L(\mathbf{r})$, can be considered as the physical manifestation of electron pairs of Lewis model. ${ }^{54,55}$

Fig. 4(a)-(c) show a radial profile of $L(\mathbf{r})$ for halogen atoms in the axial direction to the $\sigma_{\mathrm{X}-\mathrm{R}}$ bond (black lines) and in the equatorial direction to the $\sigma_{\mathrm{X}-\mathrm{R}}$ bond (red lines). It is observed that for each halogen atom, the VSCC is higher in the equatorial direction, while the axial direction shows a decrease in the density of electronic charge. This explains the dual behavior of these elements: in the equatorial direction they act as a Lewis base (nucleophile), while in the axial direction they act as a Lewis acid (electrophile). ${ }^{35-37}$ These results are consistent with the concept of positive electrostatic potential, $\sigma$-hole, proposed by Politzer. ${ }^{6}$ In addition, these results are in agreement with observations made by other authors. For example, Alkorta et al. calculated the effective radius [distance from the atom position to that where $\rho(\mathbf{r})=0.001$ a.u.] of halogen atoms in $\mathrm{Y}-\mathrm{X}(\mathrm{FCl}$,
$\mathrm{FBr}, \mathrm{ClBr}, \mathrm{F}_{2}, \mathrm{Cl}_{2}, \mathrm{Br}_{2}$ ) in the axial direction and perpendicular to the $\mathrm{Y}-\mathrm{X}$ bond, finding that the effective radius in the axial direction is smaller than in the equatorial direction. Also this difference is accentuated as the electronegativity of the atom attached to the halogen atom increases. ${ }^{29}$

The radial profile of $L(\mathbf{r})$ for the $\mathrm{X}-\mathrm{R}$ molecules is represented in Fig. 4(a)-(c). The concentration of charge of the halogens in the equatorial direction (red lines) increases in the order $\mathrm{I}<\mathrm{Br}<\mathrm{Cl}<\mathrm{F}$. It is expected that the electron donor capacity of the halogens should increase in the same order (Lewis base/ nucleophile). However, as noted above, the charge transfer, $\Delta N(\mathrm{X}-\mathrm{R})$, from the $\mathrm{X}-\mathrm{R}$ electron donor to the $\mathrm{F}-\mathrm{Br}$ electron acceptor in the $\mathrm{F}-\mathrm{Br} \cdots \mathrm{X}-\mathrm{R}$ complexes for the same $\mathrm{R}$ increases in the opposite order: $\mathrm{F}-\mathrm{Br} \cdots \mathrm{F}-\mathrm{R}<\mathrm{F}-\mathrm{Br} \cdots \mathrm{Cl}-\mathrm{R}<\mathrm{F}-\mathrm{Br} \cdots \mathrm{Br}-\mathrm{R}<$ $\mathrm{F}-\mathrm{Br} \cdots \mathrm{I}-\mathrm{R}$ (see Table 1). Therefore, the electron donor capacity of $\mathrm{X}$ is not directly dependent on the concentration of electronic charge present in its equatorial direction.

For iodine, in the I-H and I-F molecules, it is observed (see Fig. 4(c)) that in the equatorial direction (region corresponding to the location of its lone pairs), the function $L(\mathbf{r})$ exhibits a maximum in a zone of depletion of electronic charge $[L(\mathbf{r})<0]$. This is a bit contradictory, since one would expect that the maximum of the function $L(\mathbf{r})$ would take positive values. However, the appearance of this maximum in this region agrees with the existence of the $\mathrm{F}-\mathrm{Br} \cdots \mathrm{I}-\mathrm{R}$ complexes (where $\mathrm{R}=-\mathrm{H},-\mathrm{F}$ ) since in these complexes the bromine atom (Lewis acid) is connected to the lone pair of the iodine atom located in the equatorial direction.

Moreover, the inductive effects are originated by the distortion of the electronic cloud of a molecule caused by the electric field generated by neighboring molecules. In an interaction between a dipole and a nonpolar molecule, the electric field of the polar molecule distorts the electronic charge distribution of the nonpolar molecule producing an induced dipole moment. Then, the induced dipole moment interacts with the permanent dipole resulting in an attractive force. ${ }^{56}$ In this sense, the

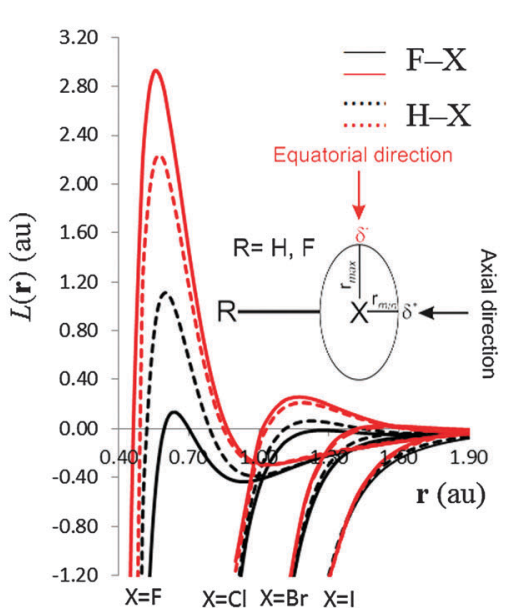

(a)

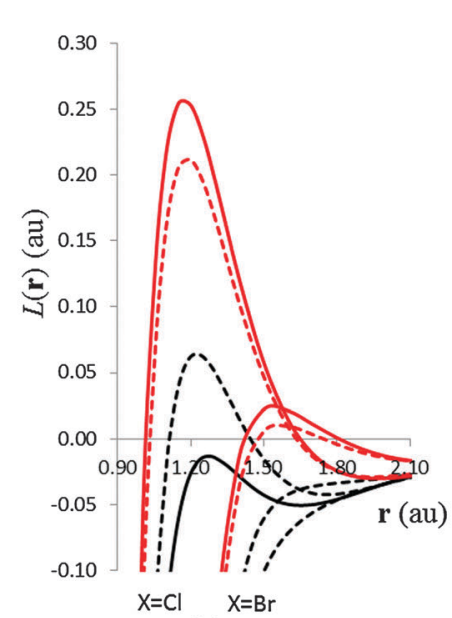

(b)

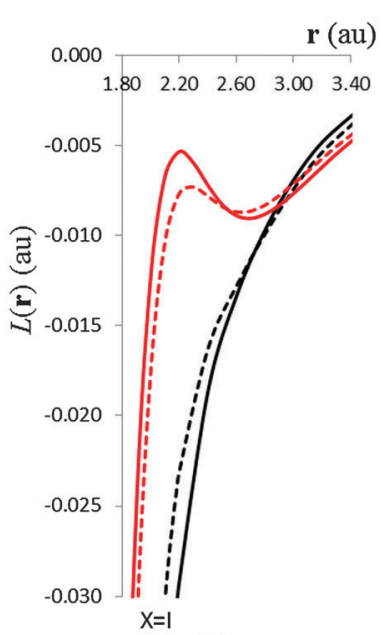

(c)

Fig. 4 Profile of the $L(\mathbf{r})=-\frac{1}{4} \nabla^{2} \rho(\mathbf{r})$ function for: (a) $X=F, C l, B r, l$; (b) $X=C l, B r$ and (c) $X=I$, in the axial direction of the $\sigma_{X-R}$ bond (black lines) and in the equatorial direction of the $\sigma_{X-R}$ bond (red lines). 


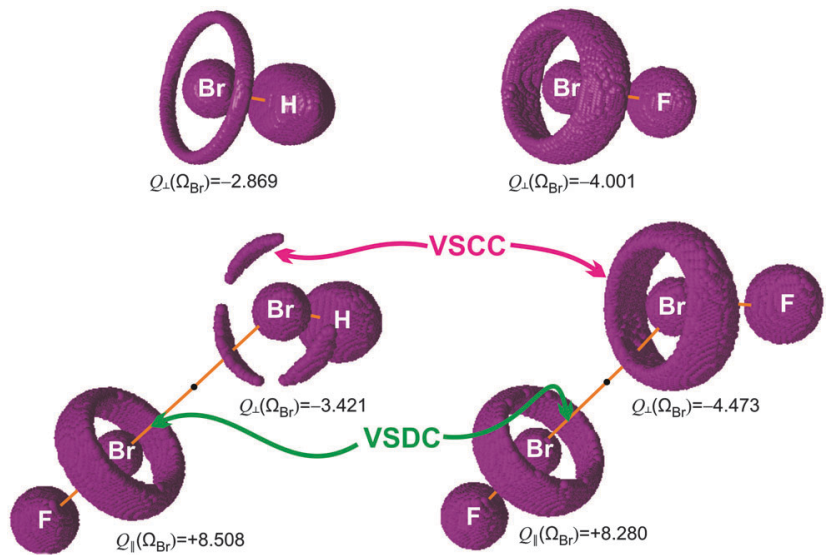

Fig. 5 Envelopes of the function $L(r)=0.0032$ a.u. for $\mathrm{Br}-\mathrm{H}$ and $\mathrm{Br}-\mathrm{F}$ isolated molecules and $\mathrm{F}-\mathrm{Br} \cdots \mathrm{Br}-\mathrm{H}$ and $\mathrm{F}-\mathrm{Br} \cdots \mathrm{Br}-\mathrm{F}$ complexes. In addition, $Q_{\perp}\left(\Omega_{\mathrm{Br}}\right)$ and $Q_{\|}\left(\Omega_{\mathrm{Br}}\right)$ quadrupole moments are reported.

topological analysis of the $L(\mathbf{r})$ function is an excellent tool to observe the rearrangement of electronic charge density on the electron donor-X atom. Fig. 5 shows the envelopes of the function $L(\mathbf{r})$ for the isolated $\mathrm{Br}-\mathrm{H}$ and $\mathrm{Br}-\mathrm{F}$ molecules and for the $\mathrm{F}-\mathrm{Br} \cdots \mathrm{Br}-\mathrm{H}$ and $\mathrm{F}-\mathrm{Br} \cdots \mathrm{Br}-\mathrm{F}$ complexes. The atomic quadrupole moments $Q_{\perp}\left(\Omega_{\mathrm{Br}}\right)$ and $Q_{\|}\left(\Omega_{\mathrm{Br}}\right)$ are also reported. In this figure the VSCC of the bromine atom in $\mathrm{Br}-\mathrm{H}$ and $\mathrm{Br}-\mathrm{F}$

Table 6 Decomposition analysis of the interaction energies obtained with the RVS methodology ${ }^{a}$

\begin{tabular}{lcrllll}
\hline Complexes & \multicolumn{1}{c}{$E_{\mathrm{ES}}$} & \multicolumn{1}{c}{$E_{\mathrm{EX}}$} & $E_{\mathrm{PL}}$ & $E_{\mathrm{CT}}$ & $E_{\text {Disp }}$ & $E_{\text {Int }}$ \\
\hline $\mathrm{FBr} \cdots \mathrm{FH}$ & -5.6 & 5.4 & -0.8 & -0.9 & -1.2 & -3.1 \\
$\mathrm{FBr} \cdots \mathrm{FF}$ & -1.1 & 2.5 & -0.3 & -0.4 & -1.6 & -1.0 \\
$\mathrm{FBr} \cdots \mathrm{ClH}$ & -6.7 & 11.3 & -1.4 & -2.9 & -3.6 & -3.3 \\
$\mathrm{FBr} \cdots \mathrm{ClF}$ & -4.1 & 9.5 & -1.1 & -2.5 & -4.2 & -2.5 \\
$\mathrm{FBr} \cdots \mathrm{BrH}$ & -8.8 & 16.1 & -1.7 & -4.5 & -4.8 & -3.7 \\
$\mathrm{FBr} \cdots \mathrm{BrF}$ & -7.1 & 16.3 & -1.8 & -4.6 & -5.4 & -2.6 \\
$\mathrm{FBr} \cdots \mathrm{IH}$ & -10.8 & 20.1 & -2.0 & -6.3 & -6.0 & -5.0 \\
$\mathrm{FBr} \cdots \mathrm{IF}$ & -10.0 & 21.6 & -2.2 & -6.5 & -6.6 & -3.7
\end{tabular}

${ }^{a}$ The $E_{\text {Disp }}$ is the difference between the MP2 interaction energy and the $\mathrm{HF}$ interaction energy. All values in $\mathrm{kcal} \mathrm{mol}^{-1}$. molecules shows an accumulation of electronic toroidal charge around the bromine atom. The toroid mentioned is larger in the molecule of $\mathrm{Br}-\mathrm{F}$, making it clear that the effect produced by the fluorine on the electronic cloud of the electron donor-X (bromine in Fig. 5) accumulates electron density in the equatorial region.

In the $\mathrm{F}-\mathrm{Br} \cdots \mathrm{Br}-\mathrm{H}$ complex, the bromine atom in the electron donor moiety modifies its VSCC, producing a considerable rearrangement of electronic charge density in the equatorial region to the $\sigma_{\mathrm{Br}-\mathrm{H}}$ bond and a discontinuity in the function $L(\mathbf{r})$. It is important to note in the $\mathrm{F}-\mathrm{Br} \cdots \mathrm{Br}-\mathrm{F}$ complex that the electron donor $\mathrm{Br}$ atom does not change its VSCC significantly compared to the isolated monomer, $\mathrm{Br}-\mathrm{F}$, based on the 0.0032 a.u. isocontour of $L(\mathbf{r})$. However, to an isovalue of $L(\mathbf{r})=0.0016$ a.u. (see Fig. S2 of the ESI $\dagger$ ) a similar situation is observed to the case of the $\mathrm{F}-\mathrm{Br} \cdots \mathrm{Br}-\mathrm{H}$ complex. The electronic charge density depletion localized over the halogen-atom bridge (Lewis acid) allows the electrostatic interaction between the nucleus of the bromine atom and the electronic cloud of the electron donor-X (Lewis base). In other words, the electron acceptor $\mathrm{Br}$ atom causes a polarization of the electronic cloud (electronic induction) on the valence shell of the electron donor-X, (bromine atom in the Fig. 5). This electronic polarization is higher in $\mathrm{F}-\mathrm{Br} \cdots \mathrm{X}-\mathrm{H}$ than in $\mathrm{F}-\mathrm{Br} \cdots \mathrm{X}-\mathrm{F}$ for the same electron donor-X.

\subsection{Energy decomposition analysis}

The analysis of RVS decomposition is summarized in Table 6. It is observed that the electrostatic interaction energies are negative in all cases, even when they occur between positively charged atoms such as $\mathrm{F}-\mathrm{Br}^{\delta+} \ldots{ }^{\delta+} \mathrm{Cl}-\mathrm{F}, \mathrm{F}-\mathrm{Br}^{\delta+} \ldots{ }^{\delta+} \mathrm{Br}-\mathrm{F}$ and $\mathrm{F}-\mathrm{Br}^{\delta+} \ldots{ }^{\delta+} \mathrm{I}-\mathrm{F}$ dimers. Moreover, in most systems studied (except for the $\mathrm{F}-\mathrm{Br}^{\delta+} \ldots \mathrm{F}-\mathrm{F}$ and $\mathrm{F}-\mathrm{Br}^{\delta+} \ldots{ }^{\delta+} \mathrm{Cl}-\mathrm{F}$ complexes) the electrostatic component is the most important. These results disagree with those reported recently by Wang et al. ${ }^{10}$ for similar systems $\left(\mathrm{F}^{-\mathrm{Br}^{\delta+}} \ldots{ }^{\delta+} \mathrm{Br}-\mathrm{F}\right.$ and $\left.\mathrm{F}-\mathrm{Br}^{\delta+} \ldots{ }^{\delta+} \mathrm{H}-\mathrm{F}\right)$. These authors conclude that the dispersion contribution plays a crucial role in the stabilities of seemingly repulsive complexes.

Fig. 6 shows the variation of the energetic components and the envelopes of the function $L(\mathbf{r})=0$ a.u. for the $\mathrm{F}-\mathrm{Br}^{\delta+} \ldots{ }^{\delta+} \mathrm{Br}-\mathrm{F}$ dimer in two different situations. In the figure it is observed that
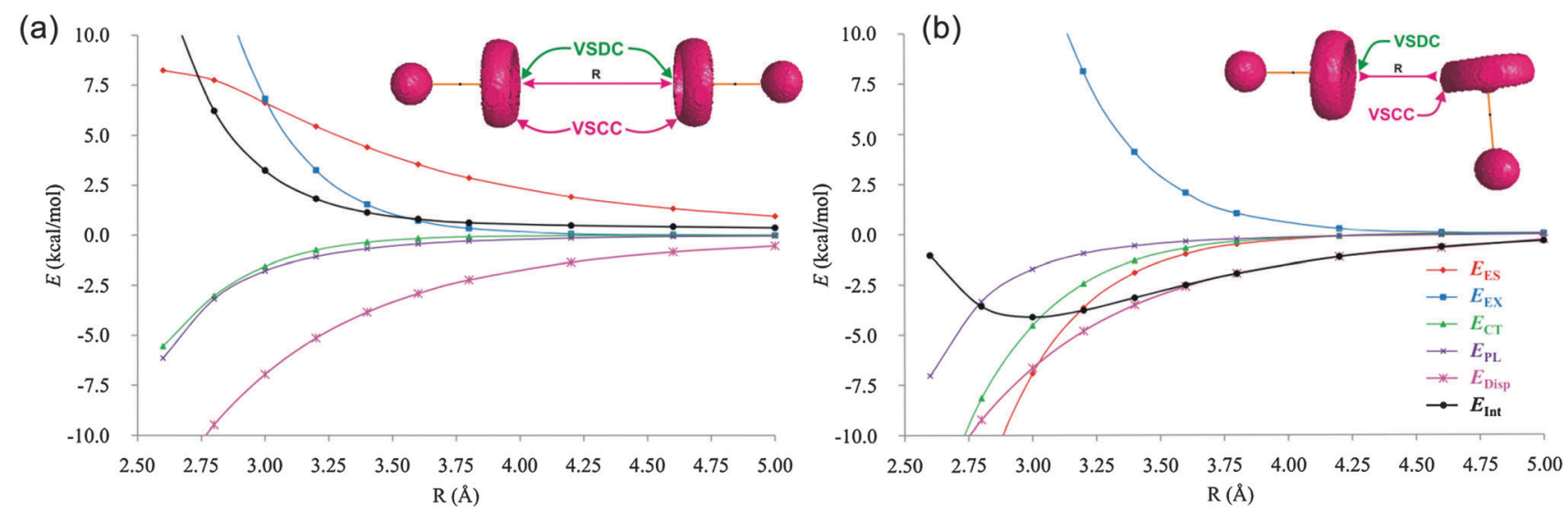

Fig. 6 Variation of interaction energy components with the intermolecular distance for the $\mathrm{F}-\mathrm{Br}^{\delta+} \ldots{ }^{\delta+} \mathrm{Br}-\mathrm{F}$ dimer, in two different orientations. Also, the envelopes of the function $L(\mathbf{r})=0$ a.u. are included in the figure. 
when the bromine atoms are close to a linear conformation, Fig. 6(a), the electrostatic component is always repulsive; this is because in this position the two interaction regions show positive values of the electrostatic potential, which causes the electrostatic term to be repulsive. When the two bromine atoms interact in an angular conformation as shown in Fig. 6(b), the electrostatic component is always attractive, since in this conformation one of the $\mathrm{F}-\mathrm{Br}$ molecules acts as electron donor, while the other acts as electron acceptor.

Additionally, Fig. 6 shows that the $E_{\mathrm{PL}}$ and $E_{\text {Disp }}$ terms have approximately similar values in both conformations, for all the intermolecular distances. This means that these components do not depend on the relative orientation of the molecules. Therefore, the dispersive and polarization forces do not influence the equilibrium conformation of these complexes. Moreover, the $E_{\mathrm{CT}}$ and $E_{\mathrm{ES}}$ components are different, in both conformations, for each intermolecular distance. These findings allow us to establish that the electrostatic forces and charge transfer play an important role not only in the stabilization of the complex, but also in the conformation of the molecular geometry of the minimum.

\section{Conclusions}

A deep theoretical study of $\mathrm{F}-\mathrm{Br} \cdots \mathrm{X}-\mathrm{R}$ interactions (with $\mathrm{X}=\mathrm{F}$, $\mathrm{Cl}$, Br, I and $\mathrm{R}=-\mathrm{H},-\mathrm{F}$ ) was carried out in order to understand the physical nature of these interactions.

A detailed analysis of MEPs reveals that considering only the static electrostatic interactions is not sufficient to explain the nature of these interactions.

The values calculated of the molecular polarizabilities suggest that the deformation capacity of the electronic cloud of the lone pairs of the electron donor-X atom plays an important role in the stability of the $\mathrm{F}-\mathrm{Br} \cdots \mathrm{X}-\mathrm{R}$ complexes studied in this work. Moreover, the nucleophilic ability of the electron donor-X halogen atom does not depend on the accumulation of electron density in the equatorial direction of the $\sigma_{\mathrm{X}-\mathrm{R}}$ bond or on the differences in electronegativity between the atoms of the electron donor molecules (X-R).

The topological analysis of electronic charge density shows a line of maximum electron density connecting the nucleus $\mathrm{Br} \cdots \mathrm{X}$, indicating that there is a stabilizing interaction between these atoms even when this occurs between positively charged atoms.

The topological analysis of the $L(\mathbf{r})$ function and the detailed analysis of the atomic quadrupole moments reveal that the $\mathrm{Br} \cdot \mathrm{X}$ interactions are electrostatic in nature. The electron acceptor bromine atom causes a polarization of the electronic cloud (electronic induction) on the valence shell of the electron donor-X.

The energy decomposition analysis reveals that in all complexes studied, the electrostatic component of the interaction energy is stabilizing. Even more, in most systems studied (except for the $\mathrm{F}-\mathrm{Br}^{\delta+} \ldots \mathrm{F}-\mathrm{F}$ and $\mathrm{F}-\mathrm{Br}^{\delta+} \ldots{ }^{\delta+} \mathrm{Cl}-\mathrm{F}$ complexes) the electrostatic component is the most important one.

Finally, the joint analysis of the variation of interaction energy components with the intermolecular distance and the $L(\mathbf{r})$ function reveals that, when the $\mathrm{F}-\mathrm{Br} \cdots \mathrm{Br}-\mathrm{F}$ complex are close to a linear conformation, the electrostatic component is always repulsive and a stable complex is not formed. When the $\mathrm{F}-\mathrm{Br} \cdots \mathrm{Br}-\mathrm{F}$ complex interacts in an angular conformation the electrostatic component is always attractive and a stable complex is formed. In addition, the electrostatic forces and charge transfer play an important role not only in the stabilization of the complex, but also in the determination of the molecular geometry of equilibrium. The dispersive and polarization forces do not influence the determination of the equilibrium conformation of the molecular geometry.

\section{Acknowledgements}

D. J. R. Duarte and N. M. Peruchena acknowledge SEGCYT UNNE and CONICET for financial support. I. Alkorta thanks Ministerio de Economia y Competitividad (Project No. CTQ201563997-C2-2-P and the Project FOTOCARBON, Ref.: S2013/MIT2841) of the Comunidad Autonoma de Madrid.

\section{References}

1 P. Politzer, P. Lane, M. C. Concha, Y. Ma and J. S. Murray, J. Mol. Model., 2007, 13, 305.

2 P. Politzer, J. S. Murray and T. Clark, Phys. Chem. Chem. Phys., 2010, 12, 7748.

3 P. Politzer, J. S. Murray and T. Clark, Phys. Chem. Chem. Phys., 2013, 15, 11178.

4 P. Metrangolo, T. Pilati and G. Resnati, CrystEngComm, 2006, 8, 946.

5 P. Politzer, K. E. Riley, F. A. Bulat and J. S. Murray, Comput. Theor. Chem., 2012, 998, 2.

6 P. Politzer and J. S. Murray, ChemPhysChem, 2013, 14, 278.

7 K. Eskandari and M. Lesani, Chem. - Eur. J., 2015, 21, 4739.

8 T. Clark, J. S. Murray and P. Politzer, Aust. J. Chem., 2014, 67, 451.

9 H. T. Qi, F. De Ren, J. L. Zhang and J. Y. Wang, J. Mol. Model., 2011, 17, 929.

10 F. F. Wang, J. H. Hou, Z. R. Li, D. Wu, Y. Li, Z. Y. Lu and W. L. Cao, J. Chem. Phys., 2007, 126, 1.

11 F. Blanco, I. Alkorta, M. Solimannejad and J. Elguero, J. Phys. Chem. A, 2009, 113, 3237.

12 C. F. Matta and R. J. Gillespie, J. Chem. Educ., 2002, 79, 1141.

13 F. Cortés-Guzmán and R. F. W. Bader, Coord. Chem. Rev., 2005, 249, 633.

14 M. J. Frisch, G. W. Trucks, H. B. Schlegel, G. E. Scuseria, M. A. Robb, J. R. Cheeseman, J. A. Montgomery, T. Vreven, K. N. Kudin, J. C. Burant, J. M. Millam, S. S. Iyengar, J. Tomasi, V. Barone, B. Mennucci, M. Cossi, G. Scalmani, N. Rega, G. A. Petersson, H. Nakatsuji, M. Hada, M. Ehara, K. Toyota, R. Fukuda, J. Hasegawa, M. Ishida, T. Nakajima, Y. Honda, O. Kitao, H. Nakai, M. Klene, X. Li, J. E. Knox, H. P. Hratchian, J. B. Cross, V. Bakken, C. Adamo, J. Jaramillo, R. Gomperts, R. E. Stratmann, O. Yazyev, A. J. Austin, R. Cammi, C. Pomelli, J. W. Ochterski, P. Y. Ayala, K. Morokuma, G. A. Voth, P. Salvador, J. J. Dannenberg, V. G. Zakrzewski, S. Dapprich, 
A. D. Daniels, M. C. Strain, O. Farkas, D. K. Malick, A. D. Rabuck, K. Raghavachari, J. B. Foresman, J. V. Ortiz, Q. Cui, A. G. Baboul, S. Clifford, J. Cioslowski, B. B. Stefanov, G. Liu, A. Liashenko, P. Piskorz, I. Komaromi, R. L. Martin, D. J. Fox, T. Keith, A. Laham, C. Y. Peng, A. Nanayakkara, M. Challacombe, P. M. W. Gill, B. Johnson, W. Chen, M. W. Wong, C. Gonzalez and J. A. Pople, 2004.

15 C. Møller and M. S. Plesset, Phys. Rev., 1934, 46, 618.

16 A. Halkier, T. Helgaker, P. Jørgensen, W. Klopper and J. Olsen, Chem. Phys. Lett., 1999, 302, 437.

17 A. Halkier, W. Klopper, T. Helgaker, P. Jørgensen and P. R. Taylor, J. Chem. Phys., 1999, 111, 9157.

18 P. Jurecka, J. Sponer, J. Cerný and P. Hobza, Phys. Chem. Chem. Phys., 2006, 8, 1985.

19 W. J. Stevens and W. H. Fink, Chem. Phys. Lett., 1987, 139, 15.

20 M. W. Schmidt, K. K. Baldridge, J. A. Boatz, S. T. Elbert, M. S. Gordon, J. H. Jensen, S. Koseki, N. Matsunaga, K. A. Nguyen, S. Su, T. L. Windus, M. Dupuis and J. A. J. Montgomery, J. Comput. Chem., 1993, 14, 1347.

21 R. F. W. Bader, Atoms in Molecules. A Quantum Theory, Clarendon, Oxford, U.K., 1990.

22 P. L. A. Popelier, Atoms in Molecules. An Introduction, Prentice-Hall, Manchester, U.K., 2000.

23 R. J. Matta and C. F. Boyd, The Quantum Theory of Atoms in Molecules: From Solid State to DNA and Drug Design, WileyVCH, Weinheim, 2007.

24 F. Blieger-König, J. Schönbohn, AIM2000, Version 2.0, chemical adviser, R. F. W. Bader, Büro fur Innovative Software Streibel Blieger-König, Germany, 2002.

25 T. A. Keith, AIMAll (Version 11.12.19), TK Gristmill Software, Overland Park KS, USA, 2011, aim.tkgristmill.com.

26 P. Murray-Rust and W. Motherwell, J. Am. Chem. Soc., 1979, 101, 4374.

27 N. Ramasubbu, R. Parthasarathy and P. Murray-Rust, J. Am. Chem. Soc., 1986, 108, 4308.

28 A. Bondi, J. Phys. Chem., 1964, 68, 441.

29 I. Alkorta, F. Blanco and J. Elguero, Struct. Chem., 2009, 20, 63.

30 P. Politzer, J. Murray, G. Janjić and S. Zarić, Crystals, 2014, 4, 12.

31 K. Eskandari and H. Zariny, Chem. Phys. Lett., 2010, 492, 9.

32 N. J. M. Amezaga, S. C. Pamies, N. M. Peruchena and G. L. Sosa, J. Phys. Chem. A, 2010, 114, 552.
33 M. D. Esrafili, M. Vakili and M. Solimannejad, J. Mol. Model., 2014, 20, 2102.

34 M. D. Esrafili and N. Mohammadirad, J. Mol. Model., 2013, 19, 2559.

35 D. J. R. Duarte, G. L. Sosa and N. M. Peruchena, J. Mol. Model., 2013, 19, 2035.

36 D. J. R. Duarte, M. M. De Las Vallejos and N. M. Peruchena, J. Mol. Model., 2010, 16, 737.

37 D. J. R. Duarte, N. M. Peruchena and I. Alkorta, J. Phys. Chem. A, 2015, 119, 3746.

38 R. F. W. Bader and H. Essen, J. Chem. Phys., 1984, 80, 1943.

39 B. G. Oliveira, F. S. Pereira, R. C. M. U. de Araújo and M. N. Ramos, Chem. Phys. Lett., 2006, 427, 181.

40 S. J. Grabowski, Chem. Phys. Lett., 2001, 338, 361.

41 E. Espinosa, I. Alkorta, J. Elguero and E. Molins, J. Chem. Phys., 2002, 117, 5529.

42 S. Jenkins and I. Morrison, Chem. Phys. Lett., 2000, 317, 97. 43 W. D. Arnold and E. Oldfield, J. Am. Chem. Soc., 2000, 122, 12835.

44 S. J. Grabowski, W. A. Sokalski and J. Leszczynski, J. Phys. Chem. A, 2006, 110, 4772.

45 E. L. Angelina and N. M. Peruchena, J. Phys. Chem. A, 2011, 115, 4701.

46 E. L. Angelina, D. J. R. Duarte and N. M. Peruchena, J. Mol. Model., 2013, 19, 2097.

47 D. J. R. Duarte, E. L. Angelina and N. M. Peruchena, J. Mol. Model., 2014, 20, 2510.

48 T. Clark, Wiley Interdiscip. Rev.: Comput. Mol. Sci., 2013, 3, 13.

49 P. Politzer, J. S. Murray and M. C. Concha, J. Mol. Model., 2008, 14, 659.

50 R. F. W. Bader, Chem. Rev., 1991, 91, 893.

51 R. F. W. Bader, J. Phys. Chem. A, 1998, 5639, 7314.

52 Z. Shi and R. J. Boyd, J. Chem. Phys., 1988, 88, 4375.

53 R. P. Sagar, A. C. T. Ku, V. H. Smith and A. M. Simas, J. Chem. Phys., 1988, 88, 4367.

54 R. J. Gillespie, Coord. Chem. Rev., 2008, 252, 1315.

55 R. F. W. Bader, S. Johnson, T.-H. Tang and P. L. A. Popelier, J. Phys. Chem., 1996, 100, 15398.

56 P. Debye, Polar Molecules, Chemical Catolog Company, New York, USA, 1929. 